\title{
Management of Outpatient Warfarin Therapy amid COVID-19 Pandemic: A Practical Guide
}

\author{
Chia Siang Kow ${ }^{1} \cdot$ Wendy Sunter ${ }^{2} \cdot$ Amie Bain $^{3,4} \cdot$ Syed Tabish Razi Zaidi ${ }^{5,6} \cdot$ Syed Shahzad Hasan ${ }^{3}$ (i)
}

Published online: 26 May 2020

(c) Springer Nature Switzerland AG 2020

\begin{abstract}
Many healthcare resources have been and continue to be allocated to the management of patients with COVID-19. Therefore, the ongoing care of patients receiving oral anticoagulation with warfarin is likely to be compromised amid this unprecedented crisis. This article discusses a stepwise algorithm for the management of outpatient warfarin therapy. Alternative management strategies are presented and discussed, including alternative pharmacological therapy options and self-monitoring. Our algorithm aims to help clinicians safely optimize the treatment of patients requiring anticoagulation therapy in the context of the global response to the current pandemic.
\end{abstract}

\section{Key Points}

Alternative management strategies for patients receiving oral anticoagulation with warfarin are presented and discussed, including alternative pharmacological therapy options and self-monitoring.

Patients receiving warfarin therapy should have their ongoing need established before a switch to direct oral anticoagulants/low-molecular-weight heparins is considered.

Self-management/self-monitoring of the international normalized ratio is highly recommended amid the COVID-19 pandemic for eligible patients (or caregivers), especially those in aged-care facilities.

Syed Shahzad Hasan

s.hasan@hud.ac.uk

1 School of Postgraduate Studies, International Medical University, Kuala Lumpur, Malaysia

2 Anticoagulant Services, Calderdale and Huddersfield NHS Foundation Trust, Huddersfield, UK

3 Department of Pharmacy, University of Huddersfield, Huddersfield, UK

4 Department of Pharmacy, Sheffield Teaching Hospitals NHS Foundation Trust, Sheffield, UK

5 School of Healthcare, University of Leeds, Leeds, UK

6 Leeds Teaching Hospitals NHS Trust, Leeds, UK

\section{Introduction}

Novel coronavirus disease 2019 (COVID-19) has become a household name, with over 2.2 million people worldwide testing positive and over 150,000 deaths as of 18 April 2020 [1]. The actual number of reported positive COVID-19 cases may underestimate the true burden because of significant differences in surveillance and diagnostic practices across the world [2]. Even within different parts of Europe, countries have different testing practices, with Germany undertaking widespread COVID-19 testing and the UK prioritizing testing of severe cases requiring hospitalization [3, 4].

While the attention of the medical community is rightly focused on managing patients with COVID-19, the ongoing care of chronically ill patients is likely to be compromised amid this unprecedented crisis. The universally adopted strategy of reducing social interaction to avoid the spread of COVID-19, termed social distancing, has considerable implications for the ongoing care of chronically ill patients $[5,6]$. Patients living with diabetes mellitus, cardiovascular diseases, respiratory diseases, and other similar chronic conditions require periodic check-ups to ensure prevention of an acute episode of illness and the effectiveness of therapy [7]. One such patient group is those receiving oral anticoagulation with warfarin as these patients need their international normalized ratio (INR) monitored regularly [8].

Data from clinical trials show that, even in a controlled trial environment with adequate monitoring and followups and dedicated research nurses, the time in therapeutic range (TTR) values achieved were only 55-64\% [9, 10]. In addition, a large retrospective cohort study of over 50,000 
patients with atrial fibrillation receiving warfarin showed that only 40,570 patients had sufficient INR results to assess TTR and less than half $(41 \%)$ of these patients had a TTR $\geq 65 \%$ [11]. As such, providing adequate monitoring of warfarin amid the worsening COVID-19 pandemic, where social distancing is increasingly emphasized, is an unprecedented challenge faced by anticoagulant service providers around the globe. The discussion that follows aims to facilitate the management of outpatient warfarin therapy by anticoagulation service providers amid the COVID-19 pandemic.

\section{Management of Outpatient Warfarin Therapy}

A stepwise algorithm for the management of outpatient warfarin therapy is proposed (Fig. 1), which complements the following discussion. A comparison of different anticoagulant strategies is depicted in Table 1.

\subsection{Establishing the Ongoing Need for Anticoagulation [Step 1]}

Warfarin is primarily initiated during hospital admission, and patients are referred to primary care for continuation and monitoring. Regardless of the setting in which warfarin is first initiated, clinicians need to assess (or reassess) the indication for warfarin as outpatient therapy. Conditions necessitating warfarin therapy include atrial fibrillation [12], cardioembolic ischemic stroke [13], prosthetic heart valve [14], venous thromboembolism (deep vein thrombosis [15] and pulmonary embolism [16]), and antiphospholipid antibody syndrome [17]. Some of these indications, such as ischemic stroke and prosthetic heart valve, require lifelong anticoagulation treatment, whereas indications such as deep vein thrombosis and pulmonary embolism may not require indefinite anticoagulation and patients should undergo careful re-evaluation of their need for ongoing warfarin therapy.

Patients with prior deep vein thrombosis or pulmonary embolism who have completed 3-6 months of warfarin therapy may be considered for cessation of treatment where appropriate. Continuing anticoagulation beyond 3-6 months is not routinely considered in patients with a provoked episode of venous thromboembolism with transient risk factors (assuming the risk factor is no longer present), isolated distal deep vein thrombosis, subsegmental or incidental pulmonary embolism, or a high risk of bleeding [18]. Patients who continue warfarin therapy indefinitely for secondary prophylaxis of venous thromboembolism require reassessment of bleeding risk, since a high/very high bleeding risk may outweigh the benefits of reducing the risk of recurrence of venous thromboembolism event with warfarin therapy. Therefore, warfarin therapy may no longer be appropriate (however, re-initiation of anticoagulation may be needed once the bleeding risk becomes reasonable) [19]. Patients with atrial fibrillation for whom sinus rhythm has been restored, either spontaneously or deliberately, also require assessment of their ongoing need for warfarin therapy. Warfarin therapy is indicated up to 4 weeks after the restoration of sinus rhythm because of the high likelihood of recurrence of atrial fibrillation in the first month after reversion to sinus rhythm and the risk of transient post-cardioversion atrial stunning in the immediate peri-cardioversion period. However, continuation of long-term warfarin therapy 4 weeks post-restoration of sinus rhythm should be guided by the $\mathrm{CHA}_{2} \mathrm{DS}_{2}-\mathrm{VASc}$ or $\mathrm{CHADS}_{2}$ score and consideration of the long-term bleeding risk using the HAS-BLED score [20-22].

\subsection{Switching from Warfarin to Direct Oral Anticoagulants [Step 2(a)]}

In patients for whom warfarin therapy is appropriately indicated and the need for warfarin is ongoing, a switch to direct oral anticoagulants (DOACs), including dabigatran, rivaroxaban, apixaban, and edoxaban, should be considered. While DOACs do require periodic renal function monitoring throughout the treatment course (at least annually or when clinically indicated), monitoring is predictable and less rigorous than the INR testing required for warfarin therapy so offers convenience for both clinicians and patients amid the COVID-19 pandemic [23]. Moreover, important additional advantages of the DOACs include the lack of susceptibility to dietary interactions and markedly reduced susceptibility to drug interactions, which somewhat alleviates the need for the intensive in-clinic patient counseling required during initiation and maintenance of warfarin therapy.

Anticoagulation with each of the DOACs (dabigatran, rivaroxaban, apixaban, and edoxaban) has led to similar or lower rates of both ischemic stroke and major bleeding compared with adjusted-dose warfarin (INR 2.0-3.0) in patients with nonvalvular atrial fibrillation in large randomized trials [24]. In addition, large randomized trials and meta-analyses have reported the safety and efficacy of these agents for the treatment and prevention of recurrent deep vein thrombosis and/or pulmonary embolism. Most of these trials were designed as noninferiority trials comparing DOACs and standard anticoagulation (i.e., heparin followed by warfarin) and showed comparable safety and efficacy [25-32].

However, DOACs are contraindicated in patients with a prosthetic mechanical valve because of the greater risk of potentially fatal valve thrombosis $[33,34]$. In addition, a switch to DOACs may be inappropriate in the following clinical situations that lack evidence or clinical experience: patients with moderate to severe mitral stenosis; antiphospholipid antibody syndrome; pregnancy, breastfeeding, or 


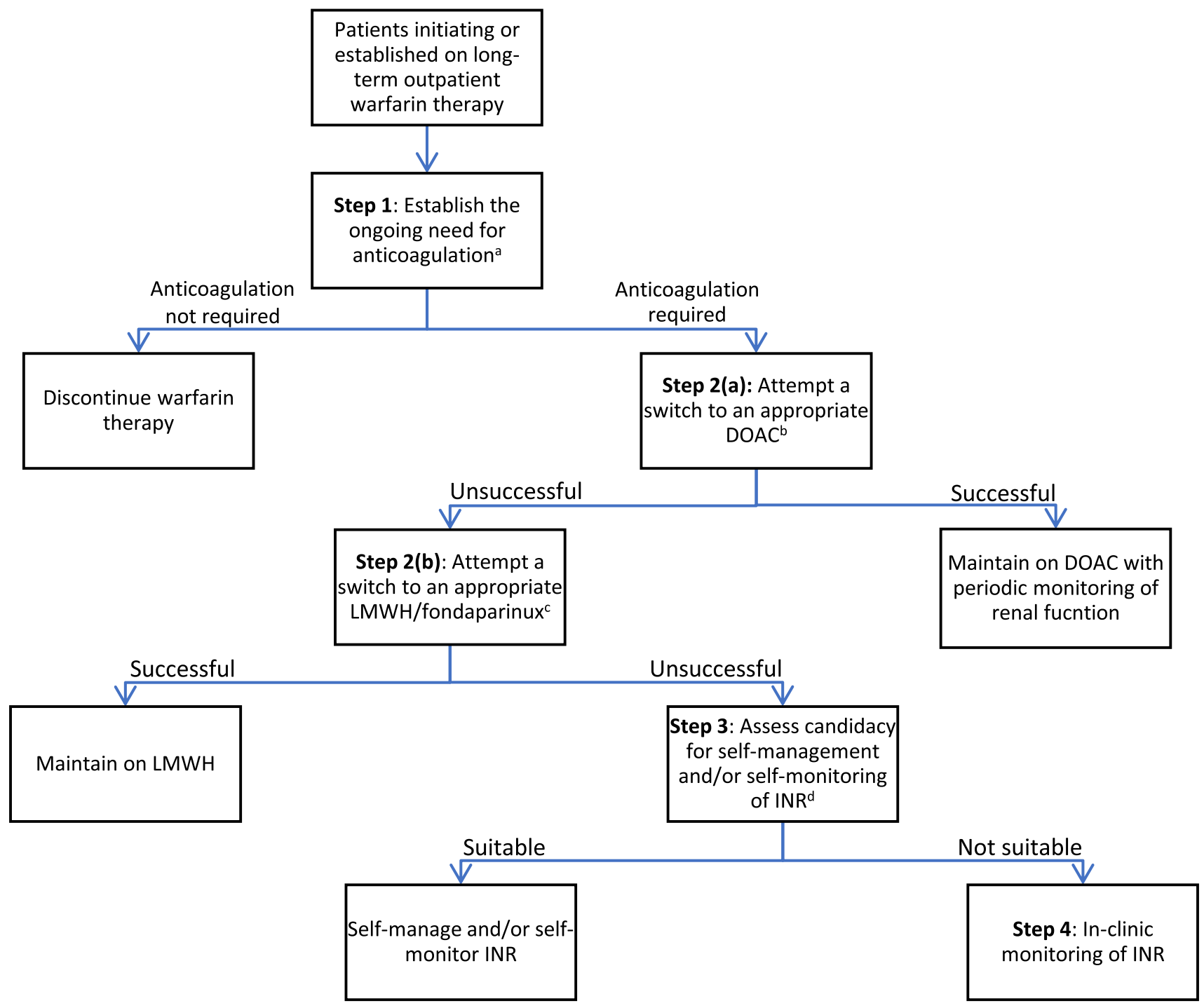

Fig. 1 A proposed stepwise algorithm for the management of outpatient warfarin therapy. DOAC direct oral anticoagulant, INR international normalized ratio, $L M W H$ low-molecular-weight heparin. ${ }^{\text {a Con- }}$ sider appropriateness of indication for warfarin therapy and current bleeding risk. ${ }^{\mathrm{b}}$ Consider contraindications, indications where DOACs might not be suitable, availability of DOACs in the formulary, and

planning a pregnancy; a target INR higher than the standard range of 2.0-3.0; severe renal impairment (creatinine clearance $<15 \mathrm{ml} / \mathrm{min}$ ); severe hepatic impairment; active malignancy/chemotherapy; extreme obesity (body mass index $>40 \mathrm{~kg} / \mathrm{m}^{2}$ or body weight $>120 \mathrm{~kg}$ ); or concurrent interacting drugs [33]. To further illustrate, DOACs are not used in patients with significant mitral valve disease because they were excluded from the clinical trials of these newer agents so further study is needed to determine the safety and efficacy of DOAC in this setting. A review of currently available data provided reassurance for the use of DOACs in patients with a body mass index $\leq 40 \mathrm{~kg} / \mathrm{m}^{2}$ or body cost issues. ${ }^{\mathrm{c} O n l y}$ for patients with venous thromboembolism. Consider personal preference, renal function, suitability for injection, and cost issues. ${ }^{\mathrm{d}}$ Consider suitability for self-managed and/or self-monitored INR, a requirement for training prior to self-managed and/or self-monitored INR, local resources, and cost issues

weight $\leq 120 \mathrm{~kg}$, but whether clinically adequate drug concentrations can be attained with standard dosing of DOACs beyond these weight parameters remains to be determined [35]. Patient-specific circumstances such as issues of affordability may also affect the uptake of DOACs, since warfarin therapy is much cheaper than DOACs. Nevertheless, generic dabigatran is available in several countries following the expiry of dabigatran's patent protection. Also, nonadherent patients are unsuitable candidates for DOACs as the short half-lives of DOACs can easily leave the patient inadequately anticoagulated compared with warfarin therapy, and 
a lack of routine monitoring means assessing adherence can be difficult $[36,37]$.

The product-specific package inserts for warfarin and DOACs differ slightly, but generally we think it is reasonable to discontinue warfarin and initiate any of the DOACs immediately when the INR is $\leq 2.0$ [38]. However, some sources maintain that, when switching from warfarin to DOACs, rivaroxaban and edoxaban can be initiated when INR is $<3.0$ and $<2.5$, respectively, upon discontinuation of warfarin [39]. Another alternative would be to start the DOAC immediately or, ideally, the next day when the INR is 2.0-2.5 [40]. However, we would emphasize that patients should only be switched from warfarin to a DOAC by clinicians with experience in managing anticoagulation.

In some settings, especially those with low resources, the supply of DOACs would be limited amid the COVID-19 pandemic. Therefore, we recommend prioritizing patients with poor control of INR, as this cohort will likely require more frequent INR checks (and so more frequent healthcare contact) to stabilize anticoagulation control.

\subsection{Switching from Warfarin to Low-Molecular-Weight Heparins/ Fondaparinux [Step 2(b)]}

For patients with venous thromboembolism with adequate renal function but in whom DOACs are contraindicated or where evidence for the use of DOACs is not established, and INR monitoring with warfarin therapy is unpractical due to COVID-19-related movement restrictions, lowmolecular-weight heparins (LMWHs) or fondaparinux are the only alternative measure. Commercially available LMWHs include enoxaparin, dalteparin, tinzaparin, bemiparin, and nadroparin. LMWHs and fondaparinux have a better correlation between dose and anticoagulant response, permitting administration of a fixed weightbased dose without close laboratory monitoring [41]. Though the need for daily subcutaneous injections may make them an undesirable option from the patient's perspective, adequate counseling and appropriate training for patients or caregivers on the correct injection technique may overcome the initial anxiety. Patients or their caregivers should be able to demonstrate the correct injecting technique after receiving appropriate training. Pharmacists involved in dispensing LMWHs should particularly ensure the most appropriate syringe size is selected for the patient, and each patient should be provided with sharps containers for the correct disposal of used syringes. Fondaparinux is supplied in prefilled syringes, so selection of syringe size is not an issue, but patients should still be provided with sharps containers.

LMWHs and fondaparinux can be administered subcutaneously in weight-based dosing for the treatment of 
venous thromboembolism $[15,18,42]$, including patients with concomitant cancer [43] requiring full anticoagulation for $\geq 3$ months. Prescribing clinicians must assess complete blood count and renal function (and serum potassium for LMWHs) before initiating LMWHs or fondaparinux and during therapy when clinically indicated. Patients should also be weighed at treatment initiation to calculate the correct dose. Nevertheless, data are sparse on whether patients with extreme obesity should be given weight-based or fixed LMWH doses, but pharmacodynamic data in patients weighing $>100 \mathrm{~kg}$ suggest that patients weighing $\leq 160 \mathrm{~kg}$ may receive a full calculated weight-based dose of LMWHs [44]. Conversely, the anticoagulation effect of fondaparinux is uncertain in patients with body mass index $>35 \mathrm{~kg} / \mathrm{m}^{2}$ [45]. Beyond these weight parameters, patients should be maintained on warfarin as their anti-Xa levels should be closely monitored to ensure effective anticoagulation, which renders the reason for switching to LMWHs or fondaparinux redundant [44]. Patients receiving LMWHs should receive appropriate education and counseling to ensure they are aware of the early symptoms of thrombocytopenia (unexplained thrombosis, necrotic skin lesions at injection sites) because LMWHs are infrequently associated with heparin-induced thrombocytopenia, with a meta-analysis reporting a rate of $1.2 \%$ in patients with venous thromboembolism [46].

Similar to DOACs, some considerations to be considered in the decision-making process is that maintaining patients on LMWHs or fondaparinux costs more than maintaining patients on warfarin (per unit price: fondaparinux > enoxaparin > warfarin), and supply of these parenteral anticoagulants may be limited during the COVID-19 pandemic, thus necessitating patient prioritization criteria.

\subsection{Assess Candidacy for Self-Management and/ or Self-Monitoring of INR [Step 3]}

Self-management and/or self-monitoring of INR among patients with warfarin therapy who could not be switched to either a DOAC or LMWH could be promoted to ease the INR monitoring workload across the healthcare system and to observe social distancing or lockdown amid the COVID-19 pandemic. Self-management involves patients self-testing their INR, with subsequent dose adjustment/ maintenance according to a predetermined dose-INR schedule. Self-monitoring requires patients to call their respective clinic for appropriate dose adjustment or maintenance advice after INR self-testing. These self-management approaches could be particularly useful in residential aged-care facilities or nursing homes in which several patients may require INR testing. Barriers to INR testing in these settings, such as difficulties in having pathology providers visit were noted even before the COVID-19 pandemic [47]. Many patients residing in aged-care facilities who are prescribed warfarin spend a considerable proportion of their time outside of the therapeutic range [48].

Small portable devices or coagulometers are available for patients to self-test their INR. When accompanied by appropriate education and training, along with consistent quality control, most patients, including older adults, can effectively and safely adjust their anticoagulant dosing [49-56]. The INR values obtained with these devices generally correlate well with laboratory measurements [57]. A 2016 review of randomized controlled trials comparing the effects and the clinical outcomes of self-monitoring or self-management of INR with standard monitoring and care, including personal physicians and anticoagulation hospitals or clinics, reported that self-testing and self-management of INR for patients receiving vitamin $\mathrm{K}$ antagonists (VKA) are valuable and effective strategies for INR control [58]. Despite an unclear relationship between INR control and clinical effects, these self-management strategies provide better control of the anticoagulant effect, improve the quality of life for patients and their families, and represent an appealing solution in terms of cost effectiveness.

A 2016 meta-analysis of randomized trials compared the clinical outcomes of standard INR monitoring to self-monitoring and/or self-management in 8950 individuals [59]. Compared with standard monitoring, those who used selfmonitoring and/or self-adjusted dosing had the following clinical outcomes over a follow-up period of 3-57 months: significantly fewer thromboembolic events (relative risk [RR] 0.58; 95\% confidence interval [CI] 0.45-0.75), no difference in major or minor bleeding events (RR 0.95 ; 95\% CI $0.8-1.12$ and RR 0.97 ; 95\% CI 0.67-1.41, respectively), and a nonsignificant trend toward reduced mortality (RR 0.85; 95\% CI 0.71-1.01).

Similarly, the burden on domiciliary pathology services could be eased amid the COVID-19 pandemic if all patients requiring warfarin therapy in a particular aged-care facility could self-monitor their INRs with the assistance of nursing staff who could also record their INR values and adjust the warfarin dose upon communication with the physician, electronically or according to a predetermined dose-INR schedule. A proof-of-concept study that implemented aged-care facility-based INR testing with electronic communication to general practitioners among residents receiving warfarin in Australia noted improved anticoagulation control for most of the residents receiving warfarin and general satisfaction from the general practitioners, nursing staff, and patients [60].

Careful selection of patients suitable for self-management and/or self-monitoring by clinicians is of utmost importance to avoid therapeutic misadventure. Such patients or caregivers should be sufficiently orientated and have the mental capacity to deal with self-management approaches, have the 
manual dexterity and physical ability to operate the coagulometer and components, have eyesight adequate to see the display screen, be contactable by phone and/or email, as preferred, and be adherent to anticoagulant therapy [61].

Before patients or their caregivers commence self-management and/or self-monitoring of INR, the anticoagulant service provider must first ensure they receive counseling to ensure an acceptable basic knowledge of warfarin, are trained in the use of the coagulometer, and are deemed competent by the trainer [62]. At initiation of self-INR testing, a venous sample or a professional point-of-care coagulometer should be used to compare results from the patient's coagulometer for at least the first two weekly INR readings to ensure the accuracy and reliability of results and allow an assessment of the patient's ability to self-monitor. While we foresee challenges in terms of training patients and undertaking quality assurance checks, in addition to purchasing equipment and providing test strips, INR self-monitoring should be considered for patients/caregivers who are capable of undergoing the required tasks to minimize INR monitoring workload across the healthcare system amid the COVID19 pandemic.

\subsection{In-Clinic Monitoring of INR [Step 4]}

The usual in-clinic monitoring of INR should be maintained for patients unable to self-monitor INR to avoid compromising the quality and safety of warfarin therapy. Outpatient INR monitoring may be performed at a laboratory or with a point-of-care device [63]. Patients initiating warfarin therapy require frequent measurements (at least two to three times per week) in accordance with institutional protocols [64]. In addition, patients with an INR value outside the therapeutic range or with frequent dose adjustments or changes in clinical status require more frequent monitoring until the dose can be stabilized (at least once weekly) [65]. Once the anticoagulant effect and dose requirements of warfarin have been stabilized for at least 1-2 weeks, the INR can be monitored less frequently, at intervals in the range of every 2-4 weeks [64, 65].

However, there may be a subpopulation of patients in whom the interval between INR testing can be further extended. Thrombosis UK guidelines suggest extending the interval between INR testing to $\geq 8$ weeks in patients whose anticoagulation is stable on warfarin with a TTR of $>60 \%$ and to 10 weeks in patients achieving a TTR of $>80 \%$ [66]. Generally, the major guidelines recommend that the interval between INR testing should not extend beyond 12 weeks, but flexibility could be allowed to monitor less frequently than every 12 weeks in the most stable patients, similar to those in clinical trial populations, during the COVID-19 pandemic, especially for patients in self-isolation because of possible COVID-19 exposure [67-69]. However, INR testing intervals should be extended cautiously in carefully selected patients because a prospective study reported that a large proportion of patients with previously stable INRs were unable to maintain stable INRs during extended-interval follow-up (every 12 weeks) [70].

Several strategies can be employed amid the COVID-19 pandemic to minimize contact time with patients requiring INR monitoring and to ease the burden on the healthcare system that may be congested with patients with COVID19. Patients who have COVID-19 symptoms before or upon arrival should be advised not to attend for monitoring. In addition, a drive-through INR testing model may be possible, but the efficacy of this model is yet to be investigated. On the other hand, provision of point-of-care INR testing devices to anticoagulation service providers to facilitate point-of-care testing may reduce workload, for example, by reducing the need to transport blood samples to laboratories. Nevertheless, they should be adequately protected by personal protective equipment (e.g., face masks, gowns, gloves), with workstations disinfected after every patient.

\section{Conclusion}

Patients newly initiated or established on long-term warfarin therapy should first undergo assessment of the ongoing need for warfarin therapy and discontinue if warfarin therapy is otherwise not or no longer indicated. Patients for whom warfarin therapy is indicated may attempt a switch to a DOAC in the absence of contraindications to DOACs and patient-specific circumstances precluding their use. LMWHs and fondaparinux are alternatives if a switch to DOACs is not possible. Self-management and/or self-monitoring of INR should be offered to patients receiving warfarin therapy where both DOACs and LMWHs/fondaparinux are not appropriate or inaccessible. Lastly, patients receiving warfarin who are unable to perform self-monitoring of INR should undergo the usual in-clinic INR monitoring, with consideration of extending the interval between INR testing among suitable patients. For patients being switched to a new anticoagulant or who will be undergoing self-monitoring of INR, standard therapeutic patient education should be provided, and consideration can be given to tele-education amid the COVID19 pandemic if local resources are available and patients are receptive to such communication method.

The need to observe social distancing or lockdown rules should not affect the quality and safety of anticoagulant therapy. Therefore, we strongly urge clinicians to ensure patients receiving warfarin therapy are appropriately managed despite the COVID-19 crisis. Hospital admission because of major bleeding or thromboembolic events due to warfarin mismanagement would expose patients to additional 
healthcare interventions and increase their potential for acquiring COVID-19.

\section{Compliance with Ethical Standards}

Funding No external funding was used in the preparation of this manuscript.

Conflict of interest Chia Siang Kow, Wendy Sunter, Amie Bain, Syed Tabish Razi Zaidi, and Syed Shahzad Hasan declare that they have no potential conflicts of interest that might be relevant to the contents of this manuscript.

\section{References}

1. Dong E, Du H, Gardner L. An interactive web-based dashboard to track COVID-19 in real-time. Lancet Infect Dis 2020. https:// coronavirus.jhu.edu/map.html. Accessed 18 April 2020.

2. Park M, Thwaites RS, Openshaw PJM. COVID-19: lessons from SARS and MERS. Eur J Immunol. 2020. https://doi.org/10.1002/ eji.202070035.

3. Morris C. Coronavirus: What can the UK learn from Germany on testing? BBC News. 2020 Apr 11. https://www.bbc.com/news/ health-52234061. Accessed 12 April 2020.

4. Public Health England. Guidance - Priorities for SARS-CoV-2 (COVID-19) testing. 2020 Apr 2. https://www.gov.uk/government /publications/wuhan-novel-coronavirus-initial-investigation-ofpossible-cases/priority-for-sars-cov-2-covid-19-testing. Accessed 12 April 2020

5. Prem K, Liu Y, Russell TW, et al. The effect of control strategies to reduce social mixing on outcomes of the COVID19 epidemic in Wuhan, China: a modelling study [published online ahead of print, 2020 Mar 25]. Lancet Public Health. 2020;S2468-2667(20)30073-6.

6. Maxmen A. How poorer countries are scrambling to prevent a coronavirus disaster. Nature. 2020;580(7802):173-4.

7. Eyre H, Kahn R, Robertson RM; ACS/ADA/AHA Collaborative Writing Committee. Preventing cancer, cardiovascular disease, and diabetes: a common agenda for theAmerican Cancer Society, the American Diabetes Association, and the American Heart Association. CA Cancer J Clin. 2004;54(4):190-207.

8. Le DT, Weibert RT, Sevilla BK, Donnelly KJ, Rapaport SI. The international normalized ratio (INR) for monitoring warfarin therapy: reliability and relation to other monitoring methods. Ann Intern Med. 1994;120(7):552-8.

9. Connolly SJ, Ezekowitz MD, Yusuf S, et al. Dabigatran versus warfarin in patients with atrial fibrillation [published correction appears in N Engl J Med. 2010 Nov 4;363(19):1877]. N Engl J Med. 2009;361(12):1139-1151.

10. Patel MR, Mahaffey KW, Garg J, et al. Rivaroxaban versus warfarin in nonvalvular atrial fibrillation. N Engl J Med. 2011;365(10):883-91.

11. McAlister FA, Wiebe N, Hemmelgarn BR. Time in therapeutic range and stability over time for warfarin users in clinical practice: a retrospective cohort study using linked routinely collected health data in Alberta, Canada. BMJ Open. 2018;8(1):e016980. Published 2018 Jan 29. doi: 10.1136/bmjopen-2017-016980

12. Lip GYH, Banerjee A, Boriani G, et al. Antithrombotic therapy for atrial fibrillation: CHEST guideline and expert panel report. Chest. 2018;154(5):1121-201.
13. Kernan WN, Ovbiagele B, Black HR, et al. Guidelines for the prevention of stroke in patients with stroke and transient ischemic attack: a guideline for healthcare professionals from the American Heart Association/American Stroke Association [published correction appears in Stroke. 2015 Feb;46(2):e54]. Stroke. 2014;45(7):2160-2236.

14. Nishimura RA, Otto CM, Bonow RO, et al. 2017 AHA/ACC Focused Update of the 2014 AHA/ACC guideline for the management of patients with valvular heart disease: a report of the American College of Cardiology/American Heart Association Task Force on Clinical Practice Guidelines. Circulation. 2017;135(25):e1159-e1195195.

15. Kearon C, Akl EA, Comerota AJ, et al. Antithrombotic therapy for VTE disease: Antithrombotic Therapy and Prevention of Thrombosis, 9th ed: American College of Chest Physicians Evidence-Based Clinical Practice Guidelines [published correction appears in Chest. 2012;142(6):1698-1704]. Chest. 2012;141(2 Suppl):e419S-e496S.

16. Konstantinides SV, Meyer G, Becattini C, et al. 2019 ESC Guidelines for the diagnosis and management of acute pulmonary embolism developed in collaboration with the European Respiratory Society (ERS). Eur Heart J. 2020;41(4):543-603.

17. Keeling D, Mackie I, Moore GW, Greer IA, Greaves M; British Committee for Standards in Haematology. Guidelines on the investigation and management of antiphospholipid syndrome. $\mathrm{Br}$ J Haematol. 2012;157(1):47-58.

18. Kearon C, Akl EA, Ornelas J, et al. Antithrombotic Therapy for VTE Disease: CHEST Guideline and Expert Panel Report [published correction appears in Chest. 2016 Oct;150(4):988]. Chest. 2016;149(2):315-352.

19. Wells PS, Forgie MA, Rodger MA. Treatment of venous thromboembolism [published correction appears in JAMA. 2014 Jun 25;311(24):2545]. JAMA. 2014;311(7):717-728.

20. January CT, Wann LS, Calkins H, et al. 2019 AHA/ACC/HRS Focused Update of the 2014 AHA/ACC/HRS Guideline for the Management of Patients With Atrial Fibrillation: A Report of the American College of Cardiology/American Heart Association Task Force on Clinical Practice Guidelines and the Heart Rhythm Society [published correction appears in J Am Coll Cardiol. 2019 Jul 30;74(4):599]. J Am Coll Cardiol. 2019;74(1):104-132.

21. Black IW, Fatkin D, Sagar KB, et al. Exclusion of atrial thrombus by transesophageal echocardiography does not preclude embolism after cardioversion of atrial fibrillation. A multicenter study. Circulation. 1994;89(6):2509-13.

22. Tejan-Sie SA, Murray RD, Black IW, et al. Spontaneous conversion of patients with atrial fibrillation scheduled for electrical cardioversion: an ACUTE trial ancillary study. J Am Coll Cardiol. 2003;42(9):1638-43.

23. Padrini R. Clinical pharmacokinetics and pharmacodynamics of direct oral anticoagulants in patients with renal failure. Eur J Drug Metab Pharmacokinet. 2019;44(1):1-12.

24. Ruff CT, Giugliano RP, Braunwald E, et al. Comparison of the efficacy and safety of new oral anticoagulants with warfarin in patients with atrial fibrillation: a meta-analysis of randomized trials. Lancet. 2014;383(9921):955-62.

25. Robertson L, Kesteven P, McCaslin JE. Oral direct thrombin inhibitors or oral factor Xa inhibitors for the treatment of pulmonary embolism. Cochrane Database Syst Rev 2015; CD010957.

26. Jun M, Lix LM, Durand M, et al. Comparative safety of direct oral anticoagulants and warfarin in venous thromboembolism: multicentre, population based, observational study. BMJ. 2017;359:j4323.

27. EINSTEIN Investigators, Bauersachs R, Berkowitz SD, et al. Oral rivaroxaban for symptomatic venous thromboembolism. N Engl J Med 2010; 363:2499. 
28. EINSTEIN-PE Investigators, Büller HR, Prins MH, et al. Oral rivaroxaban for the treatment of symptomatic pulmonary embolism. N Engl J Med 2012; 366:1287.

29. Agnelli G, Buller HR, Cohen A, et al. Oral apixaban for the treatment of acute venous thromboembolism. N Engl J Med. 2013;369:799.

30. Hokusai-VTE Investigators, Büller HR, Décousus H, et al. Edoxaban versus warfarin for the treatment of symptomatic venous thromboembolism. N Engl J Med 2013; 369:1406.

31. Schulman S, Kearon C, Kakkar AK, et al. Dabigatran versus warfarin in the treatment of acute venous thromboembolism. N Engl J Med. 2009;361:2342.

32. Schulman S, Kakkar AK, Goldhaber SZ, et al. Treatment of acute venous thromboembolism with dabigatran or warfarin and pooled analysis. Circulation. 2014;129:764.

33. Mekaj YH, Mekaj AY, Duci SB, Miftari EI. New oral anticoagulants: their advantages and disadvantages compared with vitamin $\mathrm{K}$ antagonists in the prevention and treatment of patients with thromboembolic events. Ther Clin Risk Manag. 2015;11:967-77.

34. Eikelboom JW, Connolly SJ, Brueckmann M, et al. Dabigatran versus warfarin in patients with mechanical heart valves. N Engl J Med. 2013;369(13):1206-14.

35. Moll S, Crona DJ, Martin K. Direct oral anticoagulants in extremely obese patients: OK to use? Res Pract Thromb Haemost. 2018;3(2):152-5.

36. Ieko M, Naitoh S, Yoshida M, Takahashi N. Profiles of direct oral anticoagulants and clinical usage-dosage and dose regimen differences. J Intensive Care. 2016;4:19.

37. Zirlik A, Bode C. Vitamin K antagonists: relative strengths and weaknesses vs. direct oral anticoagulants for stroke prevention in patients with atrial fibrillation. J Thromb Thrombolysis. 2017;43(3):365-379.

38. Massicotte A. A practice tool for the new oral anticoagulants [published correction appears in Can Pharm J (Ott). 2014 Sep;147(5):319]. Can Pharm J (Ott). 2014;147(1):25-32.

39. Trikha R, Kowey PR. Practical considerations for the nonvitamin $\mathrm{K}$ antagonist oral anticoagulants. Cardiology. 2017;136(2):115-124.

40. Heidbuchel H, Verhamme P, Alings M, et al. Updated European Heart Rhythm Association Practical Guide on the use of nonvitamin $\mathrm{K}$ antagonist anticoagulants in patients with non-valvular atrial fibrillation. Europace. 2015;17(10):1467-507.

41. Frydman A. Low-molecular-weight heparins: an overview of their pharmacodynamics, pharmacokinetics and metabolism in humans. Haemostasis. 1996;26(Suppl 2):24-38.

42. Baglin T, Bauer K, Douketis J, Buller H, Srivastava A, Johnson G; SSC of the ISTH. Duration of anticoagulant therapy after a first episode of an unprovoked pulmonary embolus or deep vein thrombosis: guidance from the SSC of the ISTH. J Thromb Haemost. 2012;10(4):698-702.

43. Key NS, Khorana AA, Kuderer NM, et al. Venous thromboembolism prophylaxis and treatment in patients with cancer: ASCO clinical practice guideline update. J Clin Oncol. 2020;38(5):496-520.

44. Nutescu EA, Spinler SA, Wittkowsky A, Dager WE. Lowmolecular-weight heparins in renal impairment and obesity: available evidence and clinical practice recommendations across medical and surgical settings. Ann Pharmacother. 2009;43(6):1064-83.

45. Davidson BL, Büller HR, Decousus H, et al. Effect of obesity on outcomes after fondaparinux, enoxaparin, or heparin treatment for acute venous thromboembolism in the Matisse trials. J Thromb Haemost. 2007;5(6):1191-4.

46. Morris TA, Castrejon S, Devendra G, Gamst AC. No difference in risk for thrombocytopenia during treatment of pulmonary embolism and deep venous thrombosis with either low-molecular-weight heparin or unfractionated heparin: a metaanalysis. Chest. 2007;132(4):1131-9.

47. Verhovsek M, Motlagh B, Crowther MA, et al. Quality of anticoagulation and use of warfarin-interacting medications in long-term care: a chart review. BMC Geriatr. 2008;8:13.

48. Gurwitz JH, Monette J, Rochon PA, Eckler MA, Avorn J. Atrial fibrillation and stroke prevention with warfarin in the long-term care setting. Arch Intern Med. 1997;157(9):978-84.

49. Siebenhofer A, Berghold A, Sawicki PT. Systematic review of studies of self-management of oral anticoagulation. Thromb Haemost. 2004;91:225.

50. Gardiner C, Williams K, Mackie IJ, et al. Patient self-testing is a reliable and acceptable alternative to laboratory INR monitoring. Br J Haematol. 2005;128:242.

51. Fitzmaurice DA, Murray ET, McCahon D, et al. Self management of oral anticoagulation: randomised trial. BMJ. 2005;331:1057.

52. Siebenhofer A, Rakovac I, Kleespies C, et al. Self-management of oral anticoagulation reduces major outcomes in the elderly. A randomized controlled trial. Thromb Haemost. 2008;100:1089.

53. Ryan F, Byrne S, O'Shea S. Randomized controlled trial of supervised patient self-testing of warfarin therapy using an internetbased expert system. J Thromb Haemost. 2009;7:1284.

54. Verret L, Couturier J, Rozon A, et al. Impact of a pharmacistled warfarin self-management program on quality of life and anticoagulation control: a randomized trial. Pharmacotherapy. 2012;32:871.

55. Nagler M, Raddatz-Müller P, Schmid P, et al. Accuracy of the point-of-care coagulometer CoaguChek XS in the hands of patients. J Thromb Haemost. 2013;11:197.

56. Ward A, Tompson A, Fitzmaurice D, et al. Cohort study of Anticoagulation Self-Monitoring (CASM): a prospective study of its effectiveness in the community. Br J Gen Pract. 2015;65:e428.

57. Kalçık M, Yesin M, Gürsoy MO, et al. Comparison of the INR Values measured by CoaguChek XS Coagulometer and conventional laboratory methods in patients on VKA Therapy. Clin Appl Thromb Hemost. 2017;23(2):187-94.

58. Pozzi M, Mitchell J, Henaine AM, Hanna N, Safi O, Henaine $\mathrm{R}$. International normalized ratio self-testing and self-management: improving patient outcomes. Vasc Health Risk Manag. 2016;12:387-392. Published 2016 Oct 12.

59. Heneghan CJ, Garcia-Alamino JM, Spencer EA, et al. Self-monitoring and self-management of oral anticoagulation. Cochrane Database Syst Rev. 2016;7:CD003839.

60. Bereznicki LR, Jackson SL, Kromdijk W, et al. Improving the management of warfarin in aged-care facilities utilising innovative technology: a proof-of-concept study. Int J Pharm Pract. 2014;22(1):84-91.

61. Ansell J, Jacobson A, Levy J, Völler H, Hasenkam JM; International Self-Monitoring Association for Oral Anticoagulation. Guidelines for implementation of patient self-testing and patient self-management of oral anticoagulation. International consensus guidelines prepared by International Self-Monitoring Association for Oral Anticoagulation. Int J Cardiol. 2005;99(1):37-45.

62. Jennings I, Kitchen D, Keeling D, Fitzmaurice D, Heneghan C; BCSH Committee. Patient self-testing and self-management of oral anticoagulation with vitamin $\mathrm{K}$ antagonists: guidance from the British Committee for Standards in Haematology. Br J Haematol. 2014;167(5):600-607.

63. Moiz B, Rashid A, Hasan M, Jafri L, Raheem A. Prospective comparison of point-of-care device and standard analyzer for monitoring of international normalized ratio in outpatient oral anticoagulant clinic. Clin Appl Thromb Hemost. 2018;24(7):1153-8.

64. Ansell J, Hirsh J, Hylek E, Jacobson A, Crowther M, Palareti G. Pharmacology and management of the vitamin K antagonists: American College of Chest Physicians Evidence-Based 
Clinical Practice Guidelines (8th Edition). Chest. 2008;133(6 Suppl):160S-198S.

65. Rose AJ, Ozonoff A, Berlowitz DR, Ash AS, Reisman JI, Hylek EM. Reexamining the recommended follow-up interval after obtaining an in-range international normalized ratio value: results from the Veterans Affairs study to improve anticoagulation. Chest. 2011;140(2):359-65.

66. Thrombosis UK. Anticoagulation during Covid-19. Available at: https://thrombosisuk.org/downloads/Anticoagulation\%20dur ing\%20Covid-19.pdf. Accessed 10 April 2020.

67. BSH Haemostasis and Thrombosis Task Force. INR testing for out-patients on warfarin during COVID-19 restrictions. 2020 Mar 26. https://b-s-h.org.uk/media/18170/inr-testing-for-out-patie nts-on-warfarin-during-covid-19-restrictions_26-03-2020.pdf. Accessed 10 April 2020.
68. Holbrook A, Schulman S, Witt DM, et al. Evidence-based management of anticoagulant therapy: Antithrombotic Therapy and Prevention of Thrombosis, 9th ed: American College of Chest Physicians Evidence-Based Clinical Practice Guidelines. Chest. 2012;141(2 Suppl):e152S-e184S184S.

69. Witt DM, Nieuwlaat R, Clark NP, et al. American Society of Hematology 2018 guidelines for management of venous thromboembolism: optimal management of anticoagulation therapy. Blood Adv. 2018;2:3257.

70. Carris NW, Spinelli A, Pierini D, et al. Feasibility of extendedinterval follow-up for patients receiving Warfarin. Cardiovasc Ther. 2015;33(3):98-103. 